\title{
The Risk of Cancer for Patients on Dialysis: A Review
}

\author{
Nawal E. Ragheb, Friedrich K. Port, and Ann Grossbart Schwartz \\ From the Michigan State University, College of Human Medicine, East Lansing (NER), the University of \\ Michigan, Departments of Internal Medicine and Epidemlology, and the Michigan Kidney Registry, Ann Arbor \\ (FKP), and the Michigan Cancer Foundation, Division of Epidemiology, Detroit (AGS), Michigan
}

The increased risk of cancer in immunosuppressed renal transplant recipients and the types of tumors most commonly found in these patients have been clearly documented since the first reports appeared more than 20 years ago (1-4). In contrast, the risk of cancer in patients treated by dialysis is less well established and has been a subject of some debate. This review will summarize the studies that have been conducted to discern the risk of cancer in dialysis patients; the issue of monitoring this patient population for cancer will then be addressed.

\section{A Review of the Research}

Reports have variously contended that end-stage renal disease (ESRD) patients maintained on dialysis have a risk of cancer similar to, greater than, or less than that of the general population. Despite this lack of consensus, there has been general agreement that the types of cancers diagnosed in chronically dialyzed patients are usually those found more commonly in the general population (5-11), rather than the relatively rarer tumors, such as lymphomas, reticulum cell sarcomas, liver primaries, and nonmelanoma skin cancers expressed in higher rates among transplant recipients (1-4). Table 1 provides an overview of these studies conducted on the risk of cancer among dialysis patients.

That patients on dialysis might experience an increased risk of cancer relative to the general population was suggested by Matas and colleagues (5) in a study of 78 chronic dialysis patients. Using agespecific incidence rates from another region of the United States as a comparison, the authors concluded that the observed incidence of cancer in their patient population was seven times higher than expected $(p<0.02)$. The following year, an Australian study reported that 6 of 47 patients accepted for home dialysis training were diagnosed with cancer after an average of 12 months on dialysis (6). These reports were among the first to observe that dialysis patients might experience an increased risk of cancer

Address correspondence to: Friedrich K. Port, MD, MS, 315 West Huron, Suite 340, Ann Arbor, Ml 48103.

Seminars in Dialysis-Vol 4, No 4 (Oct-Dec) 1991 pp 253257 relative to the general population, although the patient groups studied were small.

A 1977 report also suggested that maintenance dialysis might contribute in some way to an increased cancer risk (7). This larger study examined $712 \mathrm{pa}-$ tients started on hemodialysis between 1967 and 1976 at two New York dialysis units. A significant excess of both reticulum cell sarcoma (16.8 times higher than the expected incidence) and kidney cancer (risk ratio of 11.7) were found, but only among women. These initial studies were followed by additional reports, the interpretation of which suffered from the studies' examination of highly selected dialysis populations or by using a comparison with cancer mortality, rather than cancer incidence, data (8). One chart review of 499 dialysis patients, for example, found that this group's risk of malignant neoplasms was more than 3.8 times higher than expected for all types of cancer combined (9).

A larger British study included 1651 patients from six large dialysis centers (10). Using the time from first dialysis through 1976 as the study period, the only type of cancer noted to have a significant excess of incidence (and of mortality) was non-Hodgkin's lymphoma (NHL). Subsequently, a larger European Dialysis and Transplant Association Registry survey comprising data from 1086 centers in 30 countries found that the tumors most frequently diagnosed after the start of regular dialysis therapy reflected those most common in the general population (11). As in other groups of dialysis patients, this European survey found a greater than expected proportion of renal and urogenital cancers (in both sexes) than of all other sites of malignancy (11). The frequent diagnosis of genitourinary cancers was confirmed by a report on 7257 dialysis patients from the Australia and New Zealand Combined Dialysis and Transplant Registry, which also found a higher than expected incidence of lung neoplasms (12).

A nationwide Japanese survey revealed that the most frequent malignant tumor diagnosed in the dialysis population was gastric cancer (13). This finding is not unexpected as gastric cancer is most frequent among the general population in Japan. Again, a high incidence of gynecologic and urinary cancers was also noted. A more recent Japanese study reported a high incidence of renal cell carcinoma diagnosed in a prospectively followed dialysis cohort 
TABLE 1. Studies on cancer risk in dialysis patients

\begin{tabular}{|c|c|c|c|}
\hline $\begin{array}{l}\text { First Author, Year } \\
\text { (Ref.) }\end{array}$ & $\begin{array}{l}\text { Number of } \\
\text { Dialysis } \\
\text { Patients }\end{array}$ & Results (n) & Comments \\
\hline \multicolumn{4}{|c|}{ Descriptive Studies without Assessment of Risk } \\
\hline Miach, $1976(6)$ & 47 & $\begin{array}{l}\text { Tumors include: kidney (2), skin (2), stom- } \\
\text { ach (1), intestinal carcinoid (1). }\end{array}$ & $\begin{array}{l}\text { Carcinomas diagnosed after an average } \\
12 \text { months on dialysis. }\end{array}$ \\
\hline $\begin{array}{l}\text { Jacobs, } 1981 \\
\quad(11)\end{array}$ & 39,434 & $\begin{array}{l}\text { Proportionately most common tumors }(500) \\
\text { after dialysis include: prostate, bronchus, } \\
\text { and colon among males, and breast, cer- } \\
\text { vix, and bladder among females. }\end{array}$ & $\begin{array}{l}\text { A cancer prevalence survey of patients } \\
\text { treated by dialysis and/or transplanta- } \\
\text { tion. }\end{array}$ \\
\hline Sheil, 1985 (12) & 7,257 & $\begin{array}{l}\text { Genitourinary tumors, followed by those of } \\
\text { the lung, were most frequent. }\end{array}$ & $\begin{array}{l}\text { A history of cancer in } 2 \% \text { prior to di- } \\
\text { alysis. }\end{array}$ \\
\hline $\begin{array}{l}\text { O'Shea, } 1990 \\
\quad(15)\end{array}$ & 324 & $\begin{array}{l}\text { Tumors include: bladder (4), breast (3), } \\
\text { multiple myeloma (1), lung (1), liver (1), } \\
\text { kidney (1), rectum (1), unknown site (1). }\end{array}$ & $\begin{array}{l}\text { Recommend a diagnostic protocol for } \\
\text { bladder tumors for symptomatic pa- } \\
\text { tients. }\end{array}$ \\
\hline \multicolumn{4}{|c|}{ Cohort Studies with Some Assessment of Risk } \\
\hline Matas, $1975(5)$ & 646 & $\begin{array}{l}\text { Excess of all cancers combined. Tumors in- } \\
\text { clude: breast (3), kidney (2), leukemia (1), } \\
\text { lung (1), insulinoma (1), thyroid (1), cer- } \\
\text { vix in situ (1). }\end{array}$ & $\begin{array}{l}\text { Compared the cancer rates for their co- } \\
\text { hort to those of another geographic re- } \\
\text { gion. }\end{array}$ \\
\hline Slifkin, 1977 (7) & 712 & $\begin{array}{l}\text { Excess of kidney cancer }(2) \text { and reticulum } \\
\text { cell sarcoma ( } 2 \text { ) only among women. One } \\
\text { of two kidney cases was diagnosed at au- } \\
\text { topsy. }\end{array}$ & $\begin{array}{l}\text { Compared rates for all sites of cancer } \\
\text { and all ages to Third National Cancer } \\
\text { Survey data. }\end{array}$ \\
\hline $\begin{array}{l}\text { Sutherland, } \\
1977(8)\end{array}$ & 88 & $\begin{array}{l}\text { Excess of all cancers combined. Tumors in- } \\
\text { clude: kidney (1), nose (1), and splenic } \\
\text { flexure (1). }\end{array}$ & $\begin{array}{l}\text { Compared a combination of cancer inci- } \\
\text { dence and mortality rates to mortality } \\
\text { rates. }\end{array}$ \\
\hline Herr, $1979(9)$ & 499 & $\begin{array}{l}\text { Excess of all cancers combined. Tumors in- } \\
\text { clude: colon (3), multiple myeloma (2), } \\
\text { stomach (2), rectum (2), histiocytic lym- } \\
\text { phoma (2), pancreas (1), larynx (1), ovary } \\
\text { (1), unknown site (1). }\end{array}$ & $\begin{array}{l}\text { One cancer patient had previous immu- } \\
\text { nosuppressive therapy. }\end{array}$ \\
\hline $\begin{array}{l}\text { Kinlen, } 1980 \\
\quad(10)\end{array}$ & 1,651 & $\begin{array}{l}\text { Excess of all cancers combined. Tumors in- } \\
\text { clude: non-Hodgkin's lymphoma (4), kid- } \\
\text { ney (3), thyroid (2), breast (1), stomach } \\
\text { (1), bladder (1), brain (1), cervix in situ } \\
\text { (1), unknown site (1). }\end{array}$ & $\begin{array}{l}\text { Compared mortality rates to national } \\
\text { data. Compared incidence data to data } \\
\text { from a local registry. }\end{array}$ \\
\hline Ota, $1981(13)$ & 21,340 & $\begin{array}{l}\text { Urinary tract, uterine, and liver tumors } \\
\text { more common among patients on dialysis } \\
\text { than in general population. Excess mortal- } \\
\text { ity due to all cancers combined. }\end{array}$ & $\begin{array}{l}\text { Based on survey data with a } 53 \% \text { re- } \\
\text { sponse rate. }\end{array}$ \\
\hline Bush, 1984 (16) & 834 & $\begin{array}{l}\text { Number of observed cancers ( } 7) \text { lower than } \\
\text { expected }(15.6) \text {. }\end{array}$ & $\begin{array}{l}\text { Incomplete identification of hospital co- } \\
\text { hort studied. }\end{array}$ \\
\hline $\begin{array}{l}\text { Digenis, } 1986 \\
\quad(17)\end{array}$ & 328 & No evidence for an excess of cancer. & $\begin{array}{l}\text { Compared incidence data to mortality } \\
\text { data. }\end{array}$ \\
\hline $\begin{array}{l}\text { Ishikawa, } 1990 \\
\text { (14) }\end{array}$ & 96 & $\begin{array}{l}\text { Renal cell carcinoma incidence of one case } \\
\text { per } 249 \text { patient-years. }\end{array}$ & Twelve patients had a prior transplant. \\
\hline
\end{tabular}

(14). A hospital-based study of 324 dialysis patients in Spain has also confirmed the frequent diagnosis of genitourinary tumors (four urinary bladder cancers) (15). The authors recommended that a diagnostic protocol for urinary bladder tumors be followed in all symptomatic patients.

One of the few studies to conclude that the incidence of cancer is lower among uremic patients than among the general population of the same geographic area was published in 1984 (16). The study group consisted of 834 uremic patients referred to a London hospital between 1966 and 1983 for dialysis or transplantation. These findings, however, should be considered with caution, as the researchers themselves recommended, because they could not be certain of complete ascertainment of their patient cohort. Another hospital-based study, conducted in Canada, reviewed records of 328 patients treated by continuous ambulatory peritoneal dialysis from 1977 to 1985 . Although nine patients developed cancer, no excess risk was detected in this relatively small group of dialysis patients (17).

In terms of study design, three of the more recent investigations into the risk of cancer in dialysis patients can be viewed as the most comprehensive (Table 2), based on the following criteria. 1) They examine data on cancer incidence, rather than cancer mortality. This is a strength, given the inherent problems of cause of death information $(18,19)$. 2) They exclude from study any patients who were diagnosed with cancer prior to treatment by dialysis or those whose renal failure was attributed to malignancy. 3) They make use of the general population's cancer experience, by referring to the appropriate population-based cancer incidence data for statistical comparison. These studies use general population cancer-incidence data derived from the National Cancer Institute's Surveillance, Epidemiology, and End Results (SEER) program, which includes a selected sample of approximately $10 \%$ of the U.S. 
TABLE 2. Three recent studies on cancer risk in dialysis patients

\begin{tabular}{|c|c|c|c|c|}
\hline \multirow{2}{*}{ First Author, Year (Ref.) } & \multirow{2}{*}{$\begin{array}{c}\text { Number of } \\
\text { Dialysis Patients }\end{array}$} & \multicolumn{2}{|c|}{ Cancer Cases } & \multirow{2}{*}{ Results ( $p$ value) } \\
\hline & & Site & $\mathrm{n}$ & \\
\hline \multirow[t]{4}{*}{ Lindner, 1981 (18) } & 148 & Lung & 6 & $\operatorname{SIR}^{a} 2.2^{b}(<0.025)$ \\
\hline & & Kidney & 1 & \\
\hline & & Pancreas & 1 & \\
\hline & & Carcinoid & 1 & \\
\hline Kantor, 1987 (19) & 28,049 & $\begin{array}{l}\text { Non-Hodgkin's } \\
\text { lymhoma }\end{array}$ & 7 & $\mathbf{R R}^{c, d} 2.6(<0.05)$ \\
\hline \multirow{3}{*}{ Port, $1989(20)$} & 4,161 & Kidney & 6 & SIR $5.0(<0.005)$ \\
\hline & & Uterus & 6 & SIR $4.3(<0.005)$ \\
\hline & & Prostate & 13 & SIR $1.7(<0.05)$ \\
\hline
\end{tabular}

"SIR, standardized incidence ratio.

${ }^{b}$ For all cancers combined.

${ }^{c} \mathrm{RR}$, relative risk.

${ }^{d}$ Based only on patients with glomerulonephritis.

population (20). 4) They include clearly defined patient populations rather than those subject to undescribed referral patterns and other selection factors. Additionally, two of the studies $(21,22)$ incorporate the experience of dialysis patients who received a transplant, censoring their observation period at the time of transplantation. The inclusion of data on transplant recipients previously maintained on dialysis, and hence the addition of further person-years of observation, results in a more comprehensive estimate of cancer risk for dialysis patients.

In their research on 148 male patients treated at a Seattle area Veterans' Administration facility between August 1966 and July 1977, Lindner and colleagues (23) observed that nine tumors of all sites were observed when less than four were expected based on a comparison with SEER data for the Seattle area. Since six of the nine observed tumors were lung cancers, the results were adjusted for smoking status, and a significant excess incidence of all sites of cancer combined persisted.

The entire SEER data set was used to provide comparative cancer incidence data in a populationbased study of 28,049 U.S. patients treated by dialysis for at least 6 months from 1973 through 1977 , and reported to the Health Care Financing Administration (21). Tumors of the uterine cervix were excluded from analyses because their diagnosis may be a result of the frequency of medical observation. Since multiple myeloma and kidney neoplasms may explain chronic renal failure rather than arise subsequently, these tumors were excluded as well. Analyses were conducted by underlying renal disease, by interval from entry into the study, by type of dialysis, and by highest serum creatinine level prior to dialysis. A significantly elevated risk of NHL was noted among patients with glomerulonephritis; data on cytotoxic therapy, however, were not available. Moderate, but statistically insignificant, excesses of leukemia, Hodgkin's disease, thyroid, and biliary tract cancers also were observed.

A record linkage study of data collected by two population-based registries, the Michigan Kidney Registry and the Metropolitan Detroit Cancer Surveillance System (a SEER participant), reviewed the cancer experience of 4161 patients in three counties of southeastern Michigan who were treated by dialysis for ESRD between 1973 and 1984 (22). After adjusting for sex, age, race, and calendar year, a statistically significant excess of all in situ tumors combined was reported. This finding is probably a result of the increased surveillance of the patient population. More compelling was the 4.3- and 5.0fold excess of, respectively, endometrial and renal neoplasms (both $p<0.005$ ). A 1.7-fold increase ( $p$ $<0.05$ ) in prostate cancer also was observed.

Available data for dialysis patients can be summarized as suggesting an increased risk of kidney cancers $(14,22)$; endometrial uterine cancer (22); and, among patients with glomerulonephritis, NHL (21). The overall cancer risk for all sites combined may be slightly increased. It should be noted here that this risk does not include the risk for skin cancers, since many studies have not evaluated these tumors. It is clear that more research is needed to further address the risks for specific sites of cancer as well as the particular risk factors.

\section{Potential Risk Factors for Cancer in Patients on Dialysis}

A myriad of factors related to ESRD and its treatment are potential contributors to an increased risk of malignancy. Alterations in host defense as a consequence of uremia, or uremic toxins, may accelerate or amplify the development of neoplasms $(24,25)$. An accumulation of polyamines, for example, has been shown to occur in patients on chronic dialysis (26). Chemical exposures via the dialysate also have been proposed as potentially increasing the risk of cancer $(27,28)$. Ethylene oxide, used widely for gas sterilization of dialyzers (29), is classified by the International Agency for Research on Cancer as a chemical with inadequate evidence of carcinogenicity in humans, but one with sufficient evidence of carcinogenicity from animal studies (30). Additionally, the blood of dialysis patients is exposed to plasticizers, such as phthalate, and to spallation particles which exert toxic effects on the hematopoietic and macrophage/reticuloendothelial system of animals (31).

Thus, hemodialysis patients whose blood is in contact with dialyzers, tubings, and approximately 
100 liters of dialysate three times weekly have significant exposure to potential carcinogens while renal excretion and the immune system are impaired. For peritoneal dialysis patients, essentially the same factors apply except for the lack of the dialyzer and smaller dialysate volumes. The comparative risk for patients on hemodialysis versus peritoneal dialysis has not been studied adequately.

\section{Recommendations for Cancer Surveillance}

Before the issue of monitoring dialysis patients for cancer can be considered on a wide-scale basis, the question of whether these patients, or certain subgroups, are more likely than the general population to develop cancer must be resolved with greater certainty. The need to address this question in a scientifically sound fashion is well recognized (18, 32,33 ). A study large enough to adjust for the length of time on dialysis, the type of dialysis, the age at onset of ESRD and dialysis therapy, and the primary renal disease should be undertaken. In addition, the inclusion of cancer risk factors beyond those associated with dialysis should be considered in future studies designed to characterize the risk of cancer in patients treated by dialysis.

At the present time, pending more definitive population-based cohort studies, it would be premature to implement more rigorous cancer monitoring of all dialysis patients. Several studies have addressed this realm of patient care and have done so in a limited sense $(14,15,34)$. However, from the available data, one can consider some recommendations for routine monitoring of specific subgroups of dialysis patients. Patients with certain forms of glomerulonephritis are more often treated with immunosuppressive agents prior to ESRD, which may place this patient group at high risk of lymphoproliferative disease such as NHL (19). Occupational exposures to solvents and silica have been associated with ESRD (35), and such exposures also may influence malignant transformation (36). Patients with a history of such exposures should continue to be closely followed.

Certain conditions may be associated with the observed increased risk of renal neoplasms in dialysis patients (Table 3). A history of chronic analgesic use is associated with both ESRD and an increased risk of renal and other urinary tract cancers $(37,38)$. Dialysis patients with acquired cystic disease of the kidneys have been reported to be more likely to develop renal neoplasms (39-44). Since Dunnill's original observation in 1977 (39) that a large fraction of maintenance dialysis patients can develop renal cysts over time, many reports have acknowledged that associated with this is a significant risk for renal cancers (42-44). Therefore, for patients with acquired renal cysts, one could consider annual renal ultrasound or computerized tomography in addition to a routine health maintenance examination $(45$, 46). This applies mostly to patients on long-term dialysis, particularly those on dialysis 5 years or
TABLE 3. Conditions associated with an increased cancer risk among dialysis patients

\begin{tabular}{ll}
\hline \multicolumn{1}{c}{ Condition (Ref.) } & \multicolumn{1}{c}{ Cancer Site } \\
\hline Glomerulonephritis (19) & Non-Hodgkin's lymphoma \\
Analgesic nephropathy (37, 38) & Kidney, urinary tract \\
Acquired renal cysts (39-44) & Kidney \\
Prior transplant failure (47) & Non-Hodgkin's lymphoma \\
& Kaposi’s sarcoma \\
& Cervix (in situ tumors) \\
& Vulva \\
& Perineum \\
\hline
\end{tabular}

more, as the risk of cystic transformation increases with time on dialysis. Careful evaluation of the kidneys is essential, as a distinct solid lesion may be difficult to detect due to the distortion of the renal parenchyma (14).

Dialysis patients with a prior renal transplant are another subgroup of patients who may face an increased risk of cancer. These patients must be considered to have a carry-over risk from the transplant immunosuppression. The types of cancers which are most frequently diagnosed in this population include NHL (particularly reticulum cell sarcoma), Kaposi's sarcoma, in situ cervical tumors, and carcinomas of the vulva and perineum (47).

\section{Conclusion}

In comparison to the general population, patients on dialysis may experience a slightly increased risk of all types of cancers combined. Unlike transplant recipients, the types of cancers most commonly diagnosed in patients on dialysis are those most likely to be found in the general non-ESRD population. Further research is necessary to assess whether these excesses are found in dialysis patients belonging to discreet subgroups, such as those receiving a particular mode of dialysis or having a particular primary renal disease. This is underscored by the results from the study of the nationwide cohort of dialysis patients in the United States, which found a significant excess risk only for NHL among patients with glomerulonephritis. In terms of specific sites of cancer, the evidence suggests that risk may be highest for renal and genitourinary neoplasms. Additional work is needed to allow a more refined estimate to be made of the magnitude of risk that exists for specific types of cancers.

\section{Acknowledgments}

This work was supported by the National Cancer Institute (N01-CN05225), the United Foundation of Detroit, the Michigan Department of Public Health and the National Kidney Foundation of Michigan.

The authors gratefully acknowledge Dr. G. Marie Swanson's careful review of the manuscript and her suggestions.

\section{References}

1. Penn I: Malignant lymphomas in organ transplant recipients. Transplant Proc 13:736-738, 1981

2. Starzl TE, Penn I, Putnam CW, et al.: Iatrogenic alterations of immunologic surveillance in man and their influence on malignancy. Transplant Rev 7:112-145, 1971 
3. Penn I, Starzl TE: Malignant tumors arising de novo in immunosuppressed organ transplant recipients. Transplantation 14:407-417, 1972

4. Hoover R, Fraumeni JF: Risk of cancer in renal-transplant recipients. Lancet 2:55-57, 1973

5. Matas AJ, Simmons RL, Kjellstrand CM, et al.: Increased incidence of malignancy during chronic renal failure. Lancet 1:883-885, 1975

6. Miach PJ, Dawborn JK, Xipell J: Neoplasia in patients with chronic renal failure on long-term dialysis. Clin Nephrol 5:101-104, 1976

7. Slifkin RF, Goldberg J, Neff MS, et al.: Malignancy in end stage renal disease. Trans Am Soc Artif Intern Organs 23:34-39, 1977

8. Sutherland GA, Glass J, Gabriel R: Increased incidence of malignancy in chronic renal failure. Nephron $18: 182-184,1977$

9. Herr HW, Engen DE, Hostetler J: Malignancy in uremia: Dialysis versus transplantation. $J$ Urol 121:584-586, 1979

10. Kinlen LJ, Eastwood JB, Kerr DN, et al.: Cancer in patients receiving dialysis. $\mathrm{Br} \mathrm{Med} \mathrm{J} \mathrm{1:1401-1403,} 1980$

11. Jacobs C, Brunner FP, Brynger H, et al.: Malignant diseases in patients treated by dialysis and transplantation in Europe. Transplant Proc 13:729-732, 1981

12. Sheil AGR, Flavel S, Disney APS, et al.: Cancer development in patients progressing to dialysis and renal transplantation. Transplant Proc 17:1685-1688, 1985

13. Ota K, Yamashita N, Suzuki T, et al.: Malignant tumors in dialysis patients: A nationwide survey. Proc Eur Dial Transplant Assoc 18:724730,1981

14. Ishikawa I, Saito $Y$, Naoto $S$, et al.: Ten-year prospective study on the development of renal cell carcinoma in dialysis patients. Am J Kidney Dis 16:452-458, 1990

15. O'Shea ES, Molina AM, Frau JF, et al.: Cancer de vejiga y hemodialisis. Arch Esp Urol 43:359-363, 1990

16. Bush A, Gabriel R: Cancer in uremic patients. Clin Nephrol 22:77-81, 1984

17. Digenis GE, Pierratos A, Ayiomamitis A, et al.: Cancer in patients on CAPD. Peritoneal Dial Bull 6:122-124, 1986

18. Kircher T, Anderson RE: Cause of death: Proper completion of the death certificate. JAMA 258:349-352, 1987

19. Percy C, Stanek E, Gloeckler L: Accuracy of cancer death certificates and its effects on cancer mortality statistics. Am J Public Health 71:242-250, 1981

20. Young JL, Percy C, Asire A, (eds): Surveillance, Epidemiology, and End Results: Incidence and Mortality Data, 1973-1977 (National Cancer Institute Monograph No. 57), 1981

21. Kantor AF, Hoover RN, Kinlen LJ, et al.: Cancer in patients receiving long-term dialysis treatment. Am J Epidemiol 126:370-376, 1987

22. Port FK, Ragheb NE, Schwartz AG, et al.: Neoplasms in dialysis patients: A population-based study. Am J Kidney Dis 14:119-123, 1989

23. Lindner A, Farewell VT, Sherrard DJ: High incidence of neoplasia in uremic patients receiving long-term dialysis. Nephron 27:292-296, 1981

24. Goldblum SE, Reed WP: Host defenses and immunologic alterations associated with chronic hemodialysis. Ann Intern Med 93:597-613. 1980

25. Soubrane $C$, Jacobs $C$, Jacquillat $C$, et al.: Influence of the uremic state on the development of malignancy. Am J Nephrol 6:363-368, 1986
26. Newsom GD, Vugrin D: Etiologic factors in renal cell adenocarcinoma. Semin Nephrol 7:109-116, 1987

27. Bommer J, Ritz E: Water quality: A neglected problem in hemodialysis Nephron 46:1-6, 1987

28. Yanagisawa $H$, Manabe $S$, Kanaj $Y$, et al.: Carcinogenic glutamic acid pyrolysis product in the dialysate of uremic patients treated by continuous ambulatory peritoneal dialysis. Clin Nephrol 30:73-78, 1988

29. Bommer J, Ritz E: Ethylene oxide as a major cause of anaphylactoid reactions in dialysis: A review. Int $J$ Artif Organs 11:111-117, 1987

30. Swanson GM: Cancer prevention in the workplace and natural environment, a review of etiology, research design, and methods of risk reduction. Cancer 62:1725-1746, 1988

31. Bommer J, Ritz E, Andrassy K: Side effects due to materials used in hemodialysis equipment. Adv Nephrol 14:409-438, 1984

32. Pateras VR: Malignancy in chronic dialysis patients. Int $J$ Artif Organs 8:301-302, 1985

33. Wing AJ, Jacobs C, Selwood NH: Cancer and patients with end-stage renal failure (Letter). $\mathrm{Br} \mathrm{Med} J$ 284:504, 1982

34. Ajam M, Ramanujam LS, Gandhi VC, et al.: Colon-cancer screening in dialysis patients. Artif Organs 14:95-97, 1990

35. Steenland NK, Thun MJ, Ferguson WS, et al.: Occupational and other exposures associated with male end-stage renal disease: A case-control study. Am J Public Health 80:153-157, 1990

36. Nelson NA, Robins TG, Port FK: Solvent nephrotoxicity in humans and experimental animals. Am $I$ Nephrol 10:10 -20,1990

37. Bengtsson $U$, Johansson S, Angervall L: Malignancies of the urinary tract and their relation to analgesic abuse. Kidney Int 13:107-113, 1978

38. Taylor JS: Carcinoma of the urinary tract and analgesic abuse. Med J Aust 1:407-409, 1972

39. Dunnill MS, Millard PR, Oliver D: Acquired cystic disease of the kidneys: A hazard of long-term intermittent maintenance haemodialysis. J Clin Pathol 30:868-877, 1977

40. Mirahmadi MK, Vaziri ND: Cystic transformation of end-stage kidneys in patients undergoing hemodialysis. Int $J$ Artif Organs 3:267-270, 1980

41. Grantham JJ, Levine E: Acquired cystic disease: Replacing one kidney disease with another. Kidney Int 28:99-105, 1985

42. Hughson MD, Buchwald D, Fox M: Renal neoplasia and acquired cystic kidney disease in patients receiving long-term dialysis. Arch Pathol Lab Med 110:592-601, 1986

43. Bretan PN, Busch MP, Hricak $H$, et al.: Chronic renal failure: A significant risk factor in the development of acquired renal cysts and renal cell carcinoma. Cancer 57:1871-1879, 1986

44. Noronha IL, Ritz E, Waldherr R, et al.: Renal cell carcinoma in dialysis patients with acquired renal cysts. Nephrol Dial Transplant 4:763-769, 1989

45. Jabour BA, Ralls PW, Tang WW, et al:: Acquired cystic disease of the kidneys: Computed tomography and ultrasonography appraisal in patients on peritoneal and hemodialysis. Invest Radiol 22:728-732, 1987

46. Levine E, Grantham JJ, Slusher SL, et al.: CT of acquired cystic kidney disease and renal tumors in long-term dialysis patients. Urol Radiol $6: 153-157,1984$

47. Penn I: Tumors of the immunocompromised patient. Annu Rev Med 39:63-73, 1988 